\title{
Profil Penderita Hemoroid di Rumah Sakit Islam Siti Rahmah Padang Sumatera Barat Periode 2016-2017
}

\author{
Sekarlina, $\mathrm{S}^{1}$, Nurhuda, $\mathrm{M}^{2}$, Sriwahyuni ${ }^{3}$ \\ ${ }^{1}$ Mahasiswa Fakultas Kedokteran Universitas Baiturrahmah \\ e-mail: sindy.sekarlina@yahoo.com \\ ${ }^{2,3}$ Dosen Fakultas Kedokteran Universitas Baiturrahmah \\ e-mail: mnurhuda@fk.unbrah.ac.id
}

\begin{abstract}
Abstrak
Latar belakang: Hemoroid (wasir) merupakan pelebaran pleksus vaskular arteri vena yang mengelilingi bagian distal rectum dan kanal anal. Namun, kebanyakan masyarakat kurang tahu mengenai gejala-gejalanya. Data RSUP Dr. M. Djamil Padang menyatakan penderita penyakit Hemoroid pada tahun 2009 sebanyak 244 orang, tahun 2015 sampai 2016 meningkat dari 75 menjadi 109 kasus. Tujuan: Penelitian ini bertujuan untuk mengetahui profil penderita hemoroid di rumah Sakit Islam Siti Rahmah Padang periode 2016 - 2017. Metode: Penelitian deskriptif dengan menggunakan data sekunder yang berasal dari rekam medis dan data primer dari wawancara pasien. Sampel dari penelitian ini diambil dari data rekam medis RSI Siti Rahmah Padang dari November 2018 - Februari 2019, dengan jumlah sampel 45 kasus. Data diambil dengan menggunakan metode "Simple Random Sampling". Hasil: penelitian menunjukan bahwa kelompok usia tertinggi adalah kelompok usia 15-44 tahun (60\%), jenis kelamin terbanyak laki laki $(57,8 \%)$, klasifikasi hemoroid interna $(88,9 \%)$, derajat III dan IV yang masing-masingnya (32,2\%), keluhan nyeri (100\%) diikuti benjolan $(97,77 \%)$, posisi defekasi duduk $(55,5 \%)$, riwayat konstipasi $(95,6 \%)$. Kesimpulan: Pasien hemoroid tertinggi terjadi pada usia dewasa muda dengan jenis kelamin laki-laki, klasifikasi hemoroid interna pada derajat III dan IV, memiliki keluhan nyeri, posisi defekasi yaitu posisi duduk, dan mengalami konstipasi.
\end{abstract}

Kata Kunci : hemoroid, derajat, konstipasi, posisi defekasi

\begin{abstract}
Background: Hemorrhoids (wasir) are widening of venous artery plexus surrounding the distal part of the rectum and canal anal. However, most people don't know about the symptoms that arise from disease. Medical record data from RSUP Dr. M. Djamil Padang, noted that sufferers of Hemorrhoids disease in 2009 were 244 people, from 2015 to 2016 there were an increase of 75 to 109 cases. Objective: To know profile of hemorrhoids patients in Islamic Siti Rahmah Padang Hospital in 2016-2017 years. Method: The study is descriptive by using secondary data from patient's medical record and primary data from patient interview. Conducted at medical record at RSI Siti Rahmah Padang from November 2018 - February 2019, the population are 45 samples by simple random sampling technique. Results: the highest age group was the age group 15-44 years (60\%), the highest sex male (57,8\%), internal hemorrhoids classification (88.9\%), III and IV degrees with each there were (42,2\%). A history was pain (100\%) and followed by a lump of (97,77\%), defecation position is sitting (55.5\%), and constipation (95.6\%). Conclusion: The highest hemorrhoid patients occurred in young adults with the male gender, the classification of internal hemorrhoids at grade III and IV, had complaints of pain, defecation position, namely sitting position, and experiencing constipation.
\end{abstract}

Keywords: hemorrhoid, grading, constipation, defecation position. 


\section{Pendahuluan}

Menurut data WHO, jumlah penderita hemoroid di dunia pada tahun 2008 mencapai lebih dari 230 juta jiwa dan diperkirakan akan meningkat menjadi 350 juta jiwa pada tahun 2030. Angka kejadian hemoroid terjadi di seluruh negara, dengan presentasi $54 \%$ mengalami gangguan hemoroid. Berdasarkan data dari Kementerian Kesehatan di Indonesia pada tahun 2009 diperoleh 355 rata-rata kasus hemoroid dari rumah sakit di 33 provinsi. ${ }^{1}$

Data yang didapatkan dari rekam medik RSUP. Dr. M. Djamil Padang, angka kejadian hemoroid mencapai 244 kasus pada tahun 2011, sedangkan pada periode 2015 hingga 2016 didapatkan bahwa kejadian hemoroid terjadi peningkatan yaitu dari 75 orang sampai 109 orang pasien. ${ }^{2}$ Menurut hasil penelitian dari data Rumah Sakit Tingkat III Dr. Reksodiwiryo Padang diketahui bahwa jumlah penyakit hemoroid pada tahun 2017 sebanyak 174 orang. Angka ini menunjukkan bahwa angka kejadian hemoroid di Padang perlu menjadi perhatian tenaga medis. ${ }^{3}$

Faktor resiko terjadinya hemoroid adalah kurangnya konsumsi makanan berserat, konstipasi, usia, kebiasaan duduk terlalu lama, pola buang air besar yang salah, hubungan seks peranal, kurangnya intake cairan, kurang olahraga, kehamilan dan masuknya pengaruh budaya barat di Indonesia seperti pemakaian jamban duduk juga memegang peranan dalam kejadian hemorhoid. Sebab, hemorhoid dapat terjadi akibat proses mengejan berlebihan pada posisi duduk saat defekasi yang berkelanjutan. ${ }^{4,5}$

Berdasarkan uraian di atas yang menyatakan bahwa tingginya kasus hemoroid, peneliti tertarik untuk meneliti lebih jauh tentang kejadian hemoroid berdasarkan faktor-faktor yang berhubungan dengan hemoroid. Peneliti ini bertujuan untuk mengetahui profil hemoroid di Rumah Sakit Islam Siti Rahmah Padang.

\section{Metode Penelitian}

Penelitian mengenai profil penderita hemoroid di RSI Siti Rahamah Padang pada tahun 2016-2017. Penelitian ini merupakan penelitian deskriptif dengan data sekunder dari rekam medik dan data primer dari wawancara pasien. Pengambilan data dilakukan pada Maret 2018 - Februari 2019. Hasil penelitian didapatkan dari data rekam medis. Populasi penelitian ini adalah seluruh pasien hemoroid yang didiagnosis di RSI Siti Rahamah Padang pada tahun 2016-2017. Sampel dari penelitian ini diambil dari data rekam medis yang terdiagnosis hemoroid yang memenuhi kriteria inklusi. Pengambilan data dilakukan dengan metode "Simple Random Sampling”.

\section{Hasil Penelitian}

Pada penelitian ini data diambil dari data rekam medis di RSI Siti Rahamah Padang.

Tabel 1. Distribusi Frekuensi Penderita HEMOROID BERDASARKAN USIA DI RSI SITI RAHMAh PADANG

\begin{tabular}{lcc}
\hline Usia & N & \% \\
\hline Dewasa muda (15-44) Tahun & 27 & 60,0 \\
Dewasa tua (45-64) tahun & 15 & 33,3 \\
Tua $(<65)$ tahun & 3 & 6,7 \\
\hline Jumlah & 45 & 100 \\
\hline
\end{tabular}

Tabel 1 dapat disimpulkan bahwa usia terbanyak adalah dewasa muda (15-44 tahun) yaitu 27 orang (60\%) dari 45 pasien.

TAbel 2. Distribusi Frekuensi Penderita HEMOROID BERDASARKAN JENIS KELAMIN DI RSI SiTI RAHMAH PADANG

\begin{tabular}{lll}
\hline Jenis Kelamin & N & $\%$ \\
\hline
\end{tabular}




\begin{tabular}{lcc}
\hline Laki-laki & 26 & 57,8 \\
Perempuan & 19 & 42,2 \\
\hline Jumlah & 45 & 100 \\
\hline
\end{tabular}

Tabel 2 dapat disimpulkan bahwa jenis kelamin terbanyak adalah laki-laki yaitu 26 orang $(57,8 \%)$ dari 45 pasien.

TABEl 3. Distribusi FreKuensi Penderita HEMOROID BERDASARKAN KLASIFIKASI DI RSI Siti Rahmah Padang

\begin{tabular}{lcc}
\hline Klasifikasi & n & \% \\
\hline Eksterna & 26 & 11,1 \\
Interna & 19 & 88,9 \\
\hline Jumlah & 21 & 100 \\
\hline
\end{tabular}

Tabel 3 dapat disimpulkan bahwa klasifikasi hemoroid terbanyak adalah hemoroid interna yaitu 40 orang $(88,9 \%)$ dari 45 pasien.

Tabel 4. Distribusi Frekuensi Penderita HEMOROID INTERNA BERDASARKAN DERAJAT DI RSI SITI RAHMAH PADANG

\begin{tabular}{lcc}
\hline Derajat & n & \% \\
\hline I & 1 & 2.2 \\
II & 6 & 13.3 \\
III & 19 & 42,2 \\
IV & 19 & 42,2 \\
\hline Jumlah & 45 & 100 \\
\hline
\end{tabular}

Tabel 4 dapat disimpulkan bahwa derajat hemoroid interna paling banyak berada pada derajat III dan IV yaitu maisng-masing 19 orang $(84,4 \%)$ dari 45 pasien.

Tabel 5. Distribusi FrekUensi Penderita Hemoroid Berdasarkan Keluhan Pasien dI RSI SITI RAHMAH PADANG

\begin{tabular}{lcc}
\hline Keluhan & $\mathbf{N}$ & $\mathbf{\%}$ \\
\hline Nyeri & 45 & 100 \\
Benjolan & 44 & 97,77 \\
Perdarahan & 22 & 48,8 \\
\hline Jumlah & 45 & 100 \\
\hline
\end{tabular}

Tabel 5 dapat disimpulkan bahwa riwayat yang paling banyak dialami pasien adalah nyeri yaitu 45 orang (100\%) dan benjolan yaitu 44 orang $(97,77 \%)$.

Tabel 6. Distribusi Frekuensi Penderita HEMOROID BERDASARKAN RIWAYAT POSISI DEFEKASI DI RSI SITI RAHMAH PADANG

\begin{tabular}{lll}
\hline Posisi & N & $\%$ \\
\hline
\end{tabular}

\begin{tabular}{llc}
\hline Duduk & 25 & 55,5 \\
Jongkok & 20 & 44,4 \\
\hline Jumlah & 45 & 100 \\
\hline
\end{tabular}

Tabel 6 dapat disimpulkan bahwa posisi defekasi yang paling banyak berada pada posisi duduk yaitu 25 orang $(55,5 \%)$ dari 45 pasien.

Tabel 7. Distribusi Frekuensi Penderita HEMOROID BERDASARKAN RIWAYAT KONSTIPASI DI RSI SITI RAHMAH PADANG

\begin{tabular}{lcc}
\hline Konstipasi & $\mathbf{N}$ & \% \\
\hline Ya & 43 & 95,6 \\
Tidak & 2 & 4,4 \\
\hline Jumlah & 45 & 100 \\
\hline
\end{tabular}

Tabel 7 dapat disimpulkan bahwa pasien paling banyak mengalami konstipasi yaitu 43 orang $(95,6 \%)$ dari 45 pasien.

\section{Pembahasan}

Penelitian di RSI Siti Rahmah Padang menunjuukan bahwa penderita hemoroid paling banyak dengan rentang usia 15-44 tahun. Menurut penelitian yang dilakukan oleh Utomo pada tahun 2005 ditemukan terbanyak pada usia <45 tahun sebanyak 127 orang $(59,3 \%)$ dari 214 pasien $^{6}$, sama dengan penelitian oleh Alastair pada tahun 2005 ditemukan <45 tahun sebanyak 1.086 orang $(36,1 \%)$ dari 3010 pasien. $^{7}$ Berbeda pada penelitian oleh Indri pada tahun 2016 ditemukan pada usia 45-60 tahun sebanyak 32 orang $(37,6 \%)$ dari 85 pasien. ${ }^{2}$ Padatnya aktivitas yang dilakukan juga mempengaruhi terjadinya hemoroid

Jumlah kasus pada laki-laki lebih tinggi yaitu 26 orang $(57,8 \%)$. Hasil ini sesuai dengan penelitian oleh Indri menyatakan 50 orang $(58,8 \%)$ pasien laki-laki dari 85 pasien. $^{2}$ Berbeda dengan Alatair menyatakan sebanyak 1544 orang $(51,3 \%)$ dari 3010 pasien. ${ }^{7}$ Hal ini terjadi karena data yang didapatkan merupakan data hospitalize yang hanya diambil dari rumah sakit, sedangkan penelitian Alastair diambil berdasarkan populasi di negaranya. 
Berdasarkan klasifikasi pada penderita hemoroid didapatkan hasil terbanyak pada hemoroid interna sebanyak 40 orang $(88,9 \%)$. Sejalan dengan penelitian oleh Damayanti didapatkan hemoroid interna sebanyak 29 orang $(74,4 \%)$ dari 39 pasien $^{8}$, dan penelitian oleh Braunwald $\mathrm{E}$ didapatkan sebanyak yakni sebesar $77 \%$. $^{9}$

Berdasarkan derajat pada penderita hemoroid interna didapatkan hasil terbanyak pada derajat III dan IV yang masing-masingnya sebanyak 19 orang $(42,2 \%)$. Penelitian ini sejalan dengan hasil yang diperoleh oleh Putra yaitu derajat IV sebanyak 34 orang $(57,62 \%)$ dari 62 pasien. ${ }^{10}$ Namun, berbeda oleh Friedrich yaitu derajat I sebanyak 277 orang $(72,89 \%)$ dari 380 pasien. ${ }^{11}$ Hemoroid interna derajat III dan IV memiliki keluhan serta gejala yang lebih berat seperti perdarahan, benjolan, nyeri hingga rasa tidak nyaman bagi penderitanya, sehingga pasien akan datang ke rumah sakit dengan keluhan tersebut dibandingkan derajat I yang memiliki keluhan serta gejala yang lebih ringan.

Berdasarkan keluhan pasien hemoroid didapatkan hasil 45 orang (100\%) dan diikuti dengan benjolan yaitu 44 orang $(97,77 \%)$. Benjolan biasanya akan keluar dari anus pada saat pasien mengejan, tapi ada benjolan yang dapat masuk dengan sendirinya atau dapat dimasukkan kembali dengan cara menekan benjolan dengan jari dan ada juga yang sudah menetap dan tidak dapat dimasukkan kembali. Rasa nyeri pada perabaan menandakan adanya trombosis, yang biasanya disertai penyulit. ${ }^{12}$

Riwayat posisi defekasi pada penderita hemoroid didapatkan hasil posisi duduk 25 orang $(55,5 \%)$. Penelitian ini bebeda dengan Fridolin yaitu posisi jongkok sebanyak sebesar 24 orang $(44,4 \%)$ dari 54 pasien. ${ }^{13}$ Pemakaian jamban yang duduk posisi usus dan anus tidak dalam posisi tegak. Sehingga akan menyebabkan tekanan dan gesekan pada vena didaerah rectum dan anus.
Riwayat konstipasi pada penderita hemoroid didapatkan hasil 43 orang $(95,6 \%)$. Sejalan dengan penelitian oleh Fridoin yaitu terdapat 26 orang $(48,1 \%)$ dari 54 pasien yag mengalami konstipasi ${ }^{13}$ dan menurut penelitian yang dilakukan oleh Jhon menyatakan bahwa konstipasi memiliki pengaruh terhadap terjadinya hemoroid. ${ }^{14}$

\section{KESIMPULAN}

Menyatakan bahwa pasien hemoroid tertinggi terjadi pada usia dewasa muda dengan jenis kelamin laki-laki, klasifikasi hemoroid interna pada derajat III dan IV, memiliki keluhan nyeri, posisi defekasi yaitu posisi duduk, dan mengalami konstipasi.

\section{SARAN}

\section{Bagi institusi}

Perlu dilakukan peningkata kualitas data dari rekam medik baik dari kejelasan tulisan maupun kelengkapan datanya. Serta kepatuhan petugas dalam pencatatan laporan, pengumpulan berkas rekam medik, dan berikan reward dan sanksi bagi yang melanggar.

\section{Bagi masyarakat}

Diharapkan masyarakat mampu meningkatkan gerakan gaya hidup sehat yaitu memeriksakan kesehatan secara teratur, mengonsumsi sayur dan buahbuahan yang tinggi serat dan meningkatkan aktivitas fisik. Serta mengikuti penyuluhan-penyuluhan kesehatan yang diadakan di daerahnya.

\section{Bagi peneliti lain}

Perlunya dilakukan penelitian lebih lanjut agar mendapatkan hasil yang lebih akurat dengan rentang waktu data sampel yang lebih lama, dan data dari rumah sakit yang berbeda.

\section{Daftar Pustaka}

[1] Sunarto. Analisis Faktor Aktifitas Fisik Resiko Terjadi Hemoroid Di Klinik Etika. J Keperawatan Global. 2016; 1(2): 99-94. 
[2] Ranggelika, I. Gambaran Kejadian Hemoroid di RSUP. Dr. M. Djamil Padang Tahun; Universitas Baiturrahmah; 2018.

[3] Muthmainnah, A., Masrul \& Zahari, A. Peranan Diet Rendah Serat terhadap Timbulnya Hemoroid di RSUP Dr. M. Djamil Padang. J Kesehatan Andalas. 2015; 4(2):359-363.

[4] Syamsuhidayat R, J. W. Buku Ajar Bedah. Jakarta: EGC. 2010.

[5] Sya'haya, S. \& Iyos, R. N. Pengaruh Pemberian Ekstrak Daun Ungu (Graptophylum Pictum Griff) terhadap Penyembuhan Hemoroid. 2016; 5(5): 160-155.

[6] Utomo, F. D. Hubungan antara Usia dan Jenis Kelamin terhadap Derajat Hemoroid Internal di RSUD dr . Soedarso Pontianak Tahun 20092013. J Cerebellum. 2016; 2(2): 514-502.

[7] Alastair H. Maclennan, A. W. The Prevalence of Pelvic Floor Disorders and Their Relationship to Gender, Age, Parity, and Mode of Delivery.2000; 107(12): 1460-70.

[8] Safyudin, L. D. Gambaran Pasien Hemoroid di Instalasi Rawat Inap Departemen Bedah Rumah Sakit Umum Pusat Dr. Mohammad Hoesin Palembang. JKK. 2012; 4(1): 21-15

[9] Braunwald E, Hauser SL, Jameson JL. Harrison's Princples of Internal Medicine. Ed 16. New York: Mc Graw Hill. 2005: 1795-1803.

[10] Putra, OS. Pola Distribusi Kasus Hemoroid di RSUD dokter Soedarso Pontianak Periode Januari 2009 - Desember 2012; Universitas Tanjungpura; 2013.

[11] Friedrich Anton Weiser, K. S. Anal Manometric Findings in Symptomatic Hemorrhoids. 2012.

[12] Suprijono, M. A. Hemorrhoid: Universitas Islam Sultan Agung. 2009; 64(118): 38-23.

[13] Windu Fridolin, I. S. Faktor Resiko yang Berhubungan dengan Kejadian Hemoroid pada pasien di RSUD Dr. Soedarso Pontianak tahun 2011-2014. 2014.

[14] Johanson, J. F. The Prevalence of Hemorrhoids and Chronic Constipation: An Epidemiologic Study. 1990; 98(2): 380-6. 